\title{
Mathematical Modeling Applied to Drilling Engineering: An Application of Bourgoyne and Young ROP Model to a Presalt Case Study
}

\author{
Andreas Nascimento, ${ }^{1}$ David Tamas Kutas, ${ }^{2}$ Asad Elmgerbi, ${ }^{2}$ \\ Gerhard Thonhauser, ${ }^{2}$ and Mauro Hugo Mathias ${ }^{1}$ \\ ${ }^{1}$ Universidade Estadual Paulista (UNESP), Faculdade de Engenharia, Câmpus de Guaratinguetá (FEG), \\ Departamento de Mecânica (DME)/PRH48-ANP, Avenida Ariberto Pereira da Cunha 333, \\ Portal das Colinas, 12.516-410 Guaratinguetá, SP, Brazil \\ ${ }^{2}$ Montanuniversität Leoben (MUL), Department of Petroleum Engineering (DPE), Chair of Drilling and \\ Completion Engineering (CDC), Erzherzog-Johann-Straße 3, 8700 Leoben, Austria
}

Correspondence should be addressed to Andreas Nascimento; andreas.nascimento@gmail.com

Received 25 June 2015; Revised 18 August 2015; Accepted 20 August 2015

Academic Editor: Reza Jazar

Copyright (C) 2015 Andreas Nascimento et al. This is an open access article distributed under the Creative Commons Attribution License, which permits unrestricted use, distribution, and reproduction in any medium, provided the original work is properly cited.

Several mathematical ROP models were developed in the last five decades in the petroleum industry, departing from rather simple but less reliable R-W-N (drilling rate, weight on bit, and rotary speed) formulations until the arrival to more comprehensive and complete approaches such as the Bourgoyne and Young ROP model (BYM) widely used in the petroleum industry. The paper emphasizes the BYM formulation, how it is applied in terms of ROP modeling, identifies the main drilling parameters driving each subfunction, and introduces how they were developed; the paper is also addressing the normalization factors and modeling coefficients which have significant influence on the model. The present work details three simulations aiming to understand the approach by applying the formulation in a presalt layer and how some modification of the main method may impact the modeling of the fitting process. The simulation runs show that the relative error measures can be seen as the most reliable fitting verification on top of $R$-squared. Applying normalization factors and by allowing a more wide range of applicable drillability coefficients, the regression could allow better fitting of the simulation to real data from $54 \%$ to $73 \%$, which is an improvement of about $20 \%$.

\section{Introduction}

Drilling parameters such as weight on bit (WOB) and rotary speed (RPM), while performing the drilling activity itself, are, sometimes, based on normal field operation practices rather than calculated for correct optimized values. If these weights and speeds vary from the optimized values, significant drilling related costs increase may be expected and, therefore, optimization can lead to significant capital expenditure reduction. It is especially relevant in case of offshore drilling operations where rigs spend much less of total drilling time on location with actual drilling function compared to onshore operations.
Several drilling models were proposed in the past to explain the effects of drilling parameters, environment, and geology effect on the ROP. Significant research started in the end of the first half of the 20th Century and the first models were based on R-W-N (ROP, WOB, and RPM) equations, mainly driven by empirical exponents multiplied by proportionality constants to take influencing variables into account, but, later, laboratory tests revealed that R-W-N equations showed reliable results only in case of perfect hole cleaning conditions. The evolution of these modeling started basically in 1960 with Cunningham (1960), followed by a chain of changes and further researches addressed by Maurer (1962), Galle and Woods (1964), Bingham (1965), Bourgoyne Jr. and 
Young Jr. (1974), and Warren (1981), actual and subsequent models were mainly based on further improvements on top of just-mentioned root ones [1-6].

Apart of the BYM ROP model detailed in the subsequent chapters, the next equations below, by Galle and Woods
(1964) model (1) and Warren (1981) model (2), are shown as a model comparison reference and not as the main focus of the paper:

$$
\begin{aligned}
\mathrm{ROP} & =C_{f} \cdot \frac{\mathrm{WOB}_{\mathrm{sf}}{ }^{k} \cdot\left[e^{\left(-100 / \mathrm{RPM}_{\mathrm{sf}}{ }^{2}\right)} \cdot \mathrm{RPM}_{\mathrm{sf}}{ }^{b_{1}}+b_{2} \cdot \mathrm{RPM}_{\mathrm{sf}}\left(1-e^{\left(-100 / \mathrm{RPM}_{\mathrm{sf}}{ }^{2}\right)}\right)\right]}{\left(0.928125 \cdot \mathrm{OD}_{\mathrm{bit}}^{2}+6 \cdot \mathrm{OD}_{\mathrm{bit}}+1\right)^{p}}, \\
\mathrm{ROP} & =K \cdot \frac{\mathrm{RPM}_{\mathrm{sf}} \cdot\left(\mathrm{WOB}_{\mathrm{sf}}-\left(\mathrm{WOB}_{\mathrm{sf}}\right)_{t}\right)^{2}}{\mathrm{OD}_{\mathrm{bit}}^{2} \cdot S^{2}},
\end{aligned}
$$

where $b_{1}$ is 0.75 or 0.428 , for soft and hard formations, respectively [unitless]; $b_{2}$ is 0.5 or 0.2 , for soft and hard formations, respectively [unitless]; $p$ is tooth wear coefficient [unitless]; $k$ is coefficient accounting for WOB influence on ROP [unitless]; $C_{f}$ is coefficient accounting for bit type, hydraulics, drilling fluid, and formation strength [unitless]; and $K$ is constant dependent on drill-bit dullness and formation abrasiveness, as a consequence of drilling conditions [unitless].

Research and development continued, yet one of the most comprehensive ROP models is the one proposed by Bourgoyne Jr. and Young Jr. published in 1974, which considers the effects of the depth, the characteristics of the formation being drilled, the drill-bit size, the mechanical factors of the drilling process (i.e., WOB and RPM), and the mud system properties, allowing each one to be adjusted by fitting coefficients $[4,7]$.

\section{BYM ROP Model}

The model's main equation (3) consists of 8 subfunctions which act and have significant influence on the ROP performance [2]:

$$
\mathrm{ROP}=f_{1} * f_{2} * f_{3} * f_{4} * f_{5} * f_{6} * f_{7} * f_{8},
$$

where $f_{1}$ is effect of formation strength; $f_{2}$ is effect of depth and compaction; $f_{3}$ is effect of pore pressure; $f_{4}$ is effect of differential pressure; $f_{5}$ is effect of drill-bit diameter and WOB; $f_{6}$ is effect of rotary speed; $f_{7}$ is effect of drill-bit tooth wear; and $f_{8}$ is effect of bit hydraulic jet impact force. follows:

Equation (3) can be broken down into 8 subequations as

$$
\begin{aligned}
& f_{1}=e^{2.303 * a_{1}}, \\
& f_{2}=e^{2.303 * a_{2} *\left(\mathrm{TVD}_{N}-\mathrm{TVD}\right)} \\
& f_{3}=e^{2.303 * a_{3} * \mathrm{TVD}^{0.69}\left(\mathrm{EPP}-\mathrm{EPP}_{N}\right)}, \\
& f_{4}=e^{2.303 * a_{4} * \mathrm{TVD} *(\mathrm{EPP}-\mathrm{ECD})} \\
& f_{5}=\left[\frac{\mathrm{WOB}_{\mathrm{sf}} / \mathrm{OD}_{\mathrm{bit}}-\left(\mathrm{WOB}_{\mathrm{sf}} / \mathrm{OD}_{\mathrm{bit}}\right)_{t}}{\left(\mathrm{WOB}_{\mathrm{sf}} / \mathrm{OD}_{\mathrm{bit}}\right)_{N}-\left(\mathrm{WOB}_{\mathrm{sf}} / \mathrm{OD}_{\mathrm{bit}}\right)_{t}}\right]^{a_{5}},
\end{aligned}
$$

$$
\begin{aligned}
& f_{6}=\left[\frac{\mathrm{RPM}_{\mathrm{sf}}}{\left(\mathrm{RPM}_{\mathrm{sf}}\right)_{N}}\right]^{a_{6}}, \\
& f_{7}=e^{-a_{7} * h}, \\
& f_{8}=\left[\frac{F_{j}}{\left(F_{j}\right)_{N}}\right]^{a_{8}} .
\end{aligned}
$$

For the given subequations, normalization factors and coefficients are calculated being within lower and upper limits (boundary conditions), and their final values are yielded from simulations being related to specific scenarios, where data and information were gathered (see Tables 1 and 2).

2.1. Effect of Formation Strength $\left(f_{1}\right)$ and (4). The expression of $a_{1}$ primarily represents the effect of formation strength on the rate of penetration (ROP); it also represents some parameters such as drilled solids, which have not been separately modeled yet.

2.2. Effect of Formation Compaction on $\operatorname{ROP}\left(f_{2}\right)$ and (5). This term models the effect of compaction on ROP, assuming an exponential decrease in ROP with depth in a normally compacted formation. The effect of compaction on penetration rate had always been set to influence de ROP referenced to a normally compacted formation at 10,000 [ft].

2.3. Effect of Pore Pressure ROP $\left(f_{3}\right)$ and (6). This term also models the effect of compaction on ROP, assuming exponential increase of ROP with the increased pore pressure gradient. High ROP is common in formations like sandstones while low ROP is common in shale and limestones. The lower ROP is mainly related to overburden stresses, consequently adumbrating a more compacted and less porous interval.

2.4. Effect of Differential Pressure $\left(f_{4}\right)$ and (7). This term represents the effect of pressure differential across the bottom of the hole on ROP. Increased bottom hole pressure can have a negative effect on ROP because cuttings can be held on bottom, thus increasing the friction and teeth wear of the drill-bits and also decreasing the hole cleaning efficiency. The differential pressure is basically a consequence of any 
TABLE 1: Normalization values $[4,7]$.

\begin{tabular}{lcc}
\hline & Value & Unit \\
\hline$(\mathrm{TVD})_{N}$ & 10,000 & [feet] \\
\hline$(\mathrm{EPP})_{N}$ & 9.00 & [pounds/gallon] \\
\hline$\left(\mathrm{WOB}{ }_{\mathrm{sf}} / \mathrm{OD}_{\mathrm{bit}}\right)_{N}$ & 4.00 & [kilopounds/inch] \\
\hline$\left(F_{j}\right)_{N}$ & 1,000 & [pounds] \\
\hline$\left(\mathrm{RPM}_{\mathrm{sf}}\right)_{N}$ & 100 & [rotation per minute] \\
\hline
\end{tabular}

TABLE 2: Drillability coefficients $[4,7]$.

\begin{tabular}{lcc}
\hline & Lower boundary [unitless] & Upper boundary [unitless] \\
\hline$a_{1}$ & 0.5 & 1.9 \\
$a_{2}$ & 0.000001 & 0.0005 \\
$a_{3}$ & 0.000001 & 0.0009 \\
$a_{4}$ & 0.000001 & 0.0001 \\
$a_{5}$ & 0.5 & 2.0 \\
$a_{6}$ & 04 & 1.0 \\
$a_{7}$ & 0.3 & 1.5 \\
$a_{8}$ & 0.3 & 0.6 \\
\hline
\end{tabular}

increased mud densities with the given depth, which affects the equivalent mud density and further the hydraulic column pressure just on the bottom of the hole, yielding to a differential overbalance pressure increase acting against the hole cleaning. The effect of differential pressure had been referenced to 9.0 [ppg] as the limit in pressure to be considered as equalized.

2.5. Effect of Drill-Bit Diameter and WOB $\left(f_{5}\right)$ and (8). This term models the effect of drill-bit weight and diameter on penetration rate. Increased WOB has an exponential and proportional response on ROP. It should be noted that the drilling process starts after a minimal applied load (WOB threshold). Normally, after a maximum WOB (foundering point), it starts influencing negatively the ROP, basically due to the less hydraulics fed into the system which might not be high enough to clean the cuttings in the same efficiency as new hole is developed. Figure 1 gives an overview of this behaviour in which the foundering can be delayed and shifted to a higher value of applied WOB by reengineering (i.e., improving hydraulics), which is represented by (11). It is also important to highlight that the penetration rate is dependent on the hole size, where the ROP has an inversely proportional relation to the drill-bit sizes (presalt sections range normally from $8.5^{\prime \prime}$ to $12.25^{\prime \prime}$ ). The relation, based on past field experience, had always been normalized to be equal to 1.0 for 4,000 [lbf/in] of WOB over drill-bit diameter.

2.6. Effect of Rotary Speed $\left(f_{6}\right)$ and (9). This term represents the effect of rotary speed on ROP. It assumes that the increased rotary speed is directly proportional and exponential to the penetration rate. Normally, after a maximum increased RPM (foundering point), it has a negative effect on ROP; vibration can also be a responsible factor. This term had been normalized to be equal to 1.0 for 100 [rpm].

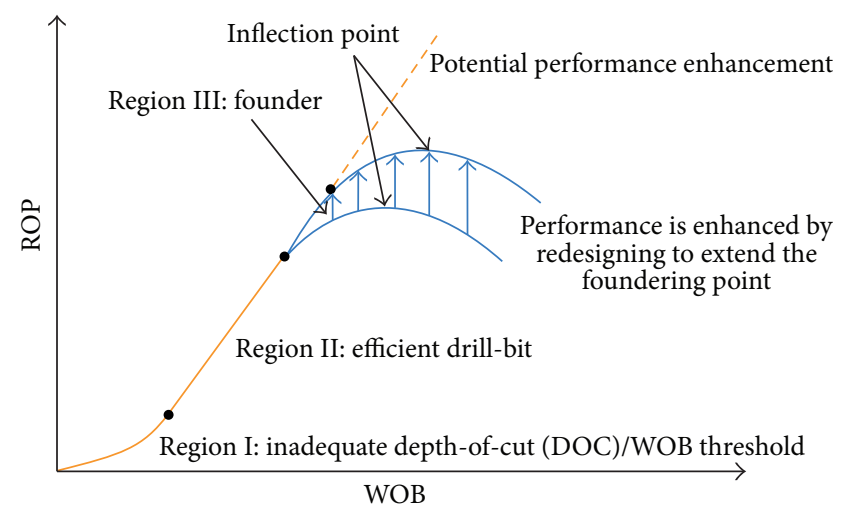

FIGURE 1: Traditional drill-rate curve highlighting optimum and maximum WOB regions (region II) [13].

2.7. Effect of Drill-Bit Tooth Wear $\left(f_{7}\right)$ and (10). The drill-bits are basically tools designed to produce a generally cylindrical hole and are broadly classified into two main types according to their primary cutting mechanism: the roller-cutter-bit type and the fixed-cutter-bit or drag-bit type. The first one applies a mechanism of fracturing or crushing the formation and consists of two or more cones (normally three) which have the cuttings elements attached to it and rotate about the axis of the cones as the drill-bit rotates at the bottom of the hole. The second type has a mechanism of scraping (shearing) or grinding the formation being drilled, having as cutting elements, normally, natural or synthetic diamond (PDC drillbits) and consisting of fixed cutters in the blades that are integrated with the body of the drill-bit which rotates as a unit with the drill-string.

This term represents the effect of the tooth wear of the drill-bit on penetration rate. The value of $a_{7}$ depends primarily on the drill-bit type and less on the geology of the formation. When carbide insert bits are used, penetration rate does not vary significantly with tooth wear. Milled tooth bits have more severe penetration rate decrease with wearing. Bourgoyne and Young defined the partial tooth wear equation as given in (8). Tooth wear is affected by formation abrasiveness, tooth geometry, bit weight, rotary speed, and the cleaning processes. It should be noted that as it is a general term, in carbonate formations like presalt layers, polycrystalline-diamond-compact (PDC) bits are mostly used.

2.8. Effect of Bit Hydraulic Jet Impact Force $\left(f_{8}\right)$ and (11). There are several types of drilling fluids widely used in the petroleum industry, each one having its specific design along the actual implicit needs. They are mainly divided into four main system types: freshwater, saltwater, oil-syntheticbased, and pneumatic. The main factor affecting either one appliance is related to the final applicability purpose, costs, environmental impact, and required technical performance. The most frequently applied type for presalt operations is the synthetic-oil-based mud (SOBM). Independently from the chosen design, they have major impact on the penetration rate, either by the solids content or by the overbalance applied 
(7) and also by the jet impact force acting just crossing the drill-bit, or more specifically, the drill-bit nozzles.

The last term models the effect of bit hydraulics on penetration rate. Increased jet force implies better cleaning of cuttings around the drill-bit teeth on the bottom of the hole and also better hydraulic environment for cutting transportation to the surface by maintaining the whole area around the drill-bit and drill-string more clean, avoiding differential sticking and decreasing the friction rate. Warren (1981) found in his microbit experiments that ROP is proportional to a Reynolds number group and that increased Reynolds number can increase the ROP [6]. Moreover, McLean (1964) and Warren (1984) experimentally showed how the drill-bit jet impact force could positively influence the ROP. This term had been normalized to be equal to 1.0 for a jet impact of 1,000 [lbf] [16-18].

\section{Practical Application of the Model}

Since 1974, when the model was originally published, measure-while-drilling (MWD) and logging-while-drilling (LWD) tools became mainstream, scientists and engineers have better understanding of downhole conditions, and cost reduction is more evident than before, driving to the fact that a better understanding of BYM could help the industry moving forward. Better understanding of the model could be achieved by a practical application and investigation.

For a better understanding of the BYM model and identification of room for improvements and/or alteration of subfunctions, already published academic sources and simulations were investigated, and several simulations were ran in presalt layers where actual field data were available. It is important to highlight that even the model was developed with the aim of optimizing ROP in more soft formations (compared to carbonate) and also with the utilization of roll-cutter-bits, there is still a way to show its applicability in different formations by changing the main normalization factors and coefficients boundaries, since these properties are crucial and with adjustments on the boundary conditions can help in the development process.

3.1. Presalt Layers. The decreasing production rate and growing demand for hydrocarbons lead the petroleum industry to explore reserves in more challenging environment. One of the places where hydrocarbon supply can be secured on the long run is located close to the shores of Brazil and on the other side of the Atlantic Ocean, close to the shores of Angola. This environment is known as presalt formations (Figure 2) [14].

The presalt denomination is used to designate carbonate geologic layers that were formed before the evaporites deposition, which has been accumulated above the carbonate layers themselves. Earlier, the hydrocarbon reserves which were found above the evaporites layers started to run out, and consequently, prospections of oil and gas in presalt layers gained interest. In 2006, in Brazil, a great reserve of oil and gas was found in a basin in similar conditions of layers that extends for approximately $800[\mathrm{~km}]$ offshore, between the city of Vitoria (State of Espirito Santo) and Florianopolis (southern region of Brazil). It is likely that the greatest presalt reserves in the world are found there in the northeast to south of Brazil, in the Gulf of Mexico and in Africa's West Coast close to the shores of Angola [14]. These presalt clusters structure (from Brazil and Africa) were developed around 160 million years ago, from the separation of the continental superstructure Gondwana (part of Pangea supercontinent) into the American and African continents. Figure 3 shows a similarity indication in which the presalt carbonate geological formations from Brazilian Santos and Campos Basin are located relatively close to the shores of South America, being also evidenced on the African side since South America and Africa have common geological history.

The rifting created the conditions which were necessary for the deposition of sediments: sea water (secured low energy and high salinity environment) started to fill up the space between the formerly attached continents, which favorably influenced the development of bacteria colonies. The secretion of these bacteria, allied with the precipitation of carbonate salts, created nuclei for the formation of microbialites (carbonate rocks), on which hydrocarbons could accumulate. Normally, most accumulations in these regions have presalt origin, but, in some cases, the salt slips and opens way for them to migrate allowing them to accumulate in the postsalt rocks. Even though they have the same origin, they may have some differences; that is, in the postsalt case, bacteria could consume the lighter part of the oil, from which gasoline and diesel are extracted. For the presalt oil, a high reservoir of rocks such as coquinas and volcaniclastics, allied with a higher temperature, above $80\left[{ }^{\circ} \mathrm{C}\right.$ ] (given the greater depths), creates a condition that sterilizes the oil and preserves its qualities, thus lighter oil and gas are expected to be found [14]. This phenomenon can be especially important for Brazil since its already discovered reserves were mainly heavy oil reserves which are not beneficial for refineries to prepare diesel fuel, and, therefore, in the last couple of decades crude and other refined petroleum products were imported to Brazil. Nevertheless, light oil or natural gas exploration and extraction from presalt layers in the Santos and Campos basins could have an impact for changing this situation.

As it was emphasized in the introduction, exploration of presalt layers is a highly challenging enterprise. The main difficulties are operations in ultradeep water $(1,500[\mathrm{~m}]$ and deeper), reservoir locations deeper than 5,000 [m], expansion over large areas with high gas-oil ratio, high pressure and low temperature, and lying below thick evaporites layers (approximately 2,000 [m] thick in some regions), mainly located offshore-up to $300[\mathrm{~km}]$ off the coast with harsh oceanic conditions. Table 3 highlights some characteristics of these carbonate rocks from different publications.

3.2. Simulation with Originally Suggested Drillability Coefficients and Normalization Factors. Simulation were established based on presalt actual drilling field data. The originally suggested starting coefficients and normalization values were used with the help of Microsoft Excel 2010 and Oracle Crystal Ball Version 11.2.2. softwares. Crystal Ball is a Microsoft Excel add-on application for predictive modeling, forecasting simulation, and formulation optimization. The input data 
TABLE 3: Main rock properties of presalt carbonates [8-11].

\begin{tabular}{lcccccccc}
\hline \multirow{2}{*}{ Author } & \multirow{2}{*}{ Publication year } & \multicolumn{2}{c}{ Porosity [\%] } & \multicolumn{2}{c}{ Permeability [mD] } & \multirow{2}{*}{ Approximate depth [m] } & \multirow{2}{*}{ Field name } \\
& & Lower value & Upper value & Lower value & Upper value & & Sao Paulo Plateau \\
& 2008 & 9 & 12 & & 100 & & $5,000-6,500$ & Buracica/Picarras \\
Carminatti et al. [8] & 2011 & 2 & 15 & N/A & N/A & $3,000-5,500$ & Jiquia/Tapema \\
Mello et al. [9] & 2011 & 2 & 14 & N/A & N/A & $3,000-5,500$ & N/A \\
Mello et al. [9] & 2012 & 9 & 12 & & 100 & & $5,000-6,500$ & \\
Johann et al. [10] & & & & & & &
\end{tabular}

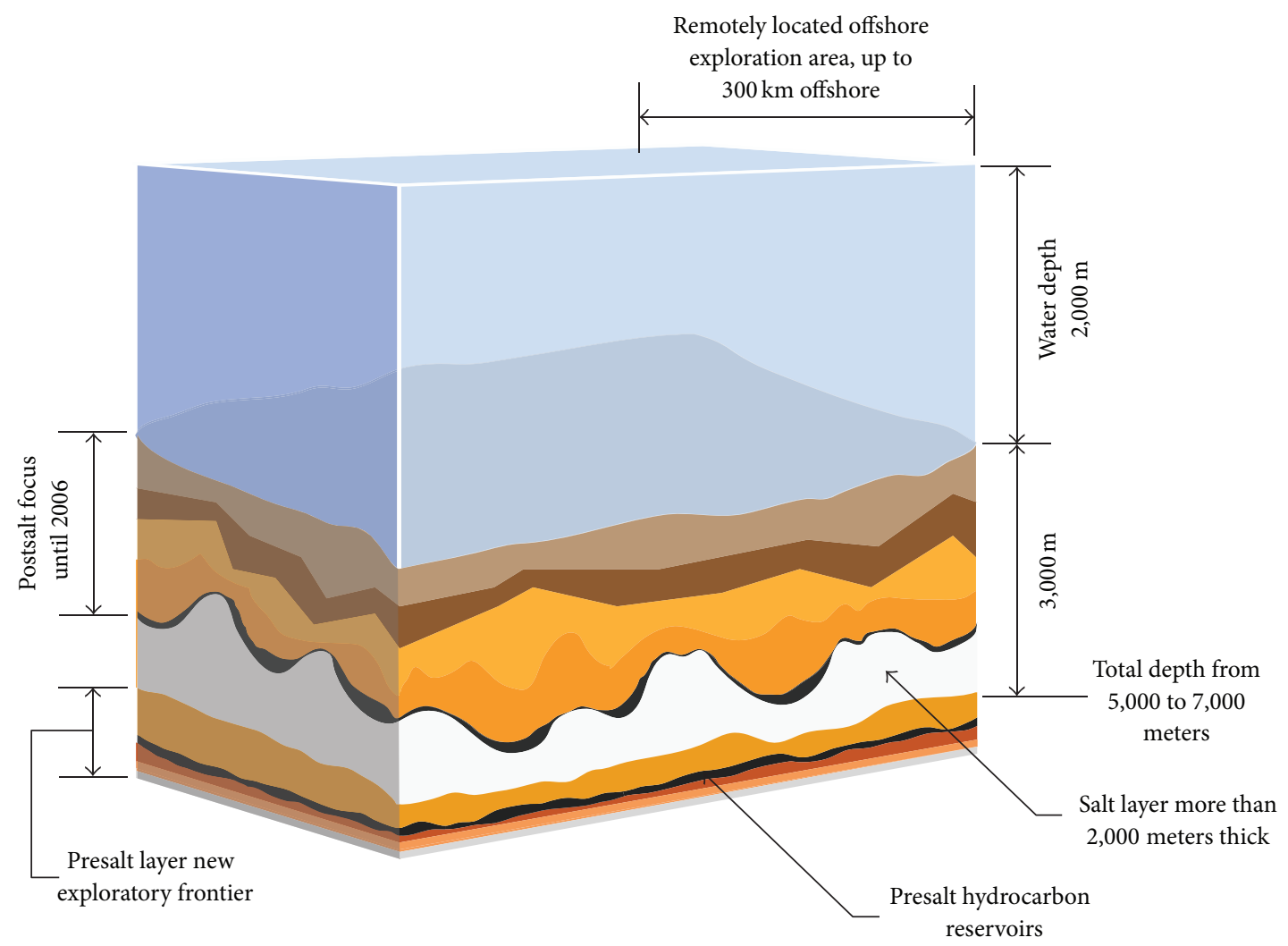

FIGURE 2: Schematic of a presalt layer location and its surroundings [14].

used were the originally suggested drillability coefficients (with lower and upper boundaries) and the actual measured ROP values. Crystal Ball recomputed the drillability coefficients for the best possible fitting to actual field ROP data (targeting $R$-squared to 1 ), while normalization factors were unchanged. Table 4 and Figure 4 detail the first results. The graph represents that the results are only depth-based (not time-based).

$R$-squared enables researchers to test hypotheses or predict future outcomes by statistically measuring how close the original data are to the fitted regression line. In regression, this parameter is a statistical measure of how well the regression line approximates the real data points:

$$
R^{2}=1-\frac{\sum_{i}\left(\mathrm{ROP}_{\text {field } \_i}-\mathrm{ROP}_{\text {calc } \__{-}}\right)^{2}}{\sum_{i}\left(\mathrm{ROP}_{\text {field } i}-\overline{\mathrm{ROP}}_{\text {field }}\right)^{2}}
$$

Relative error has also been calculated for results comparison purposes. Relative error is the ratio of an error in a measured or calculated quantity to the magnitude of that quantity:

$$
\text { Relative Error }=\frac{\overline{\sum_{i} \mid\left(\mathrm{ROP}_{\text {field } \__{i}}-\mathrm{ROP}_{\text {calc } \left.\_i_{i}\right) \mid}\right.}}{\overline{\mathrm{ROP}}_{\text {field }}} .
$$

The results show adequate values; however, from the $R$ squared, meaningful conclusions cannot be derived since they are out of the normally accepted range [0 to 1] (-1.94). Nevertheless, publications have shown that $R$-squared is not the most reliable solution to evaluate results of nonlinear regression trends. However, in the same time, relative error shows more adequate results with the value of 0.50 (Figure 4). Considering the fact that the $R$-squared was not a reliable way to measure the fitting, another simulation was run with the aim of getting the relative error as close as possible to 0 instead of $R$-squared as close as possible to 1 (Table 5 and Figure 5). 


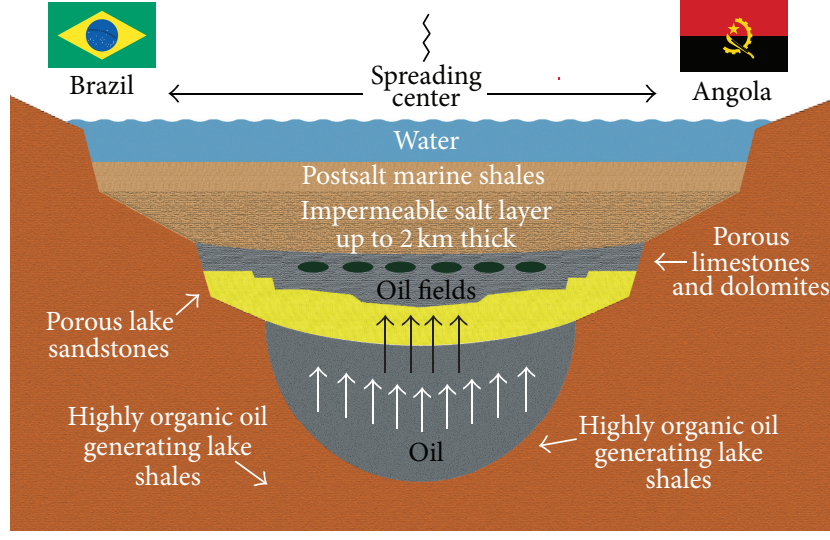

FIgURE 3: Presalt occurrences schematic emphasising Brazil and Angola [15].

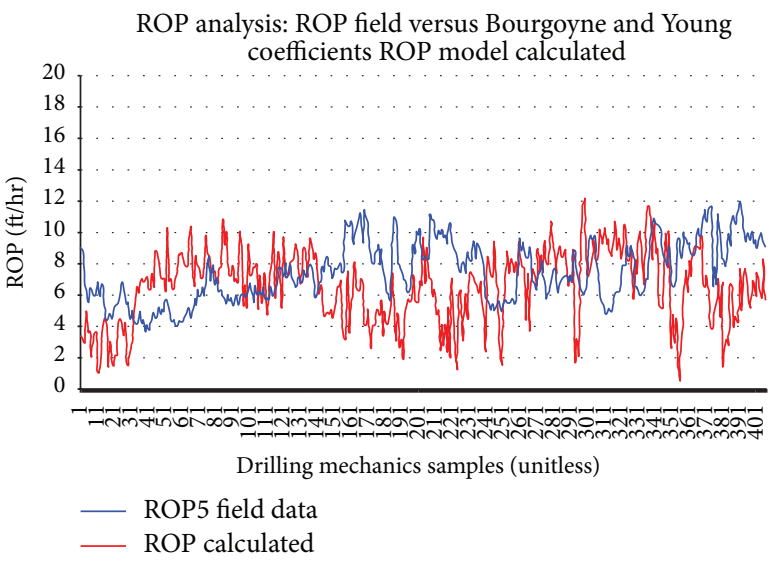

FIGURE 4: Result graph of the simulation with originally suggested drillability coefficients and normalization values, with the depthbased ROP plotting.

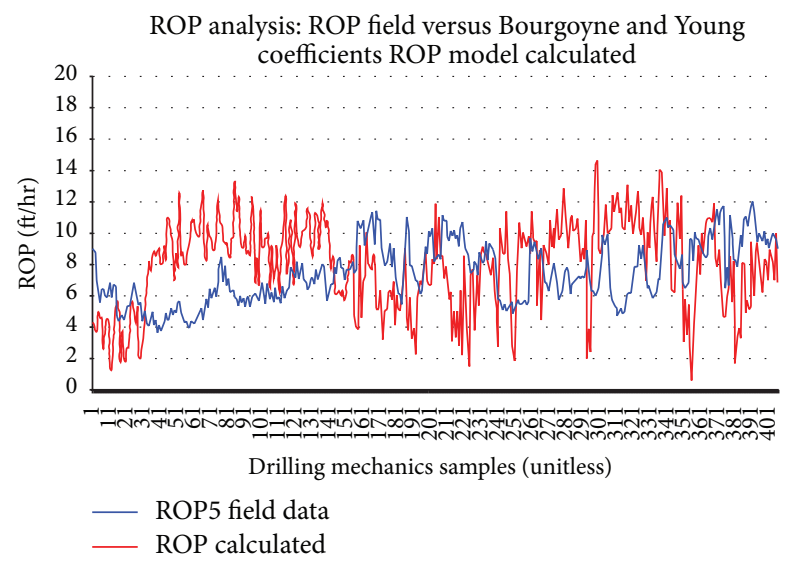

FIGURE 5: Result graph of the simulation with originally suggested drillability coefficients and normalization values with the aim of minimizing relative error, with depth-based ROP plotting.
TABLE 4: Results of the simulation with originally suggested drillability coefficients and normalization values.

\begin{tabular}{lccc}
\hline & $\begin{array}{c}\text { Lower } \\
\text { boundary } \\
\text { [unitless] }\end{array}$ & $\begin{array}{c}\text { Upper } \\
\text { boundary } \\
\text { [unitless] }\end{array}$ & $\begin{array}{c}\text { Calculated } \\
\text { coefficients } \\
\text { [unitless] }\end{array}$ \\
\hline$a_{1}$ & 0.5 & 1.9 & 0.986866 \\
$a_{2}$ & 0.000001 & 0.0005 & 0.000001 \\
$a_{3}$ & 0.000001 & 0.0009 & 0.000900 \\
$a_{4}$ & 0.000001 & 0.0001 & 0.000001 \\
$a_{5}$ & 0.5 & 2.0 & 0.500000 \\
$a_{6}$ & 04 & 1.0 & 0.702963 \\
$a_{7}$ & 0.3 & 1.5 & 0.300000 \\
$a_{8}$ & 0.3 & 0.6 & 0.599998 \\
$R$-squared & & -1.9388546 & \\
Relative error & & 0.5067288 & \\
\hline
\end{tabular}

TABLE 5: Results of the simulation with originally suggested drillability coefficients and normalization values with the aim of minimizing the relative error.

\begin{tabular}{lccc}
\hline & $\begin{array}{c}\text { Lower } \\
\text { boundary } \\
\text { [unitless] }\end{array}$ & $\begin{array}{c}\text { Upper } \\
\text { boundary } \\
\text { [unitless] }\end{array}$ & $\begin{array}{c}\text { Calculated } \\
\text { coefficients } \\
\text { [unitless] }\end{array}$ \\
\hline$a_{1}$ & 0.5 & 1.9 & 1.083550 \\
$a_{2}$ & 0.000001 & 0.0005 & 0.000001 \\
$a_{3}$ & 0.000001 & 0.0009 & 0.000900 \\
$a_{4}$ & 0.000001 & 0.0001 & 0.000001 \\
$a_{5}$ & 0.5 & 2.0 & 0.500000 \\
$a_{6}$ & 04 & 1.0 & 0.651057 \\
$a_{7}$ & 0.3 & 1.5 & 0.300000 \\
$a_{8}$ & 0.3 & 0.6 & 0.402447 \\
$R$-squared & & -2.6091334 & \\
Relative error & & 0.4572496 & \\
\hline
\end{tabular}

Based on the obtained values, the relative error shows more adequate matching than in case of the first simulation with 0.46 on top of $0.51 ; R$-squared shows -2.61 compared to -1.94 , confirming the unreliability of $R$-squared based evaluation. Based on the experience and gained knowledge of the two simulation runs, a third one was established to investigate the behaviour of the BYM with different starting parameters.

3.3. Simulation with Modified Drillability Coefficients and Normalization Factors. From the originally published normalization factors and parameters other academic sources were investigated to verify how the original model has been alternated over the years. It is important because understanding the development way of the BYM can help to establish a better fitting simulation and identify possible ways for further model improvement, allowing room for consistent change suggestions. Table 6 summarizes the most important parameters gathered (normalization values, drillability coefficients, and $R$-squared values), final results can be observed later, in Figure 6. 
TABLE 6: BYM applied parameters from different academic sources.

\begin{tabular}{lccc}
\hline Parameter & $\begin{array}{c}\text { Normalization } \\
\text { factor }\end{array}$ & $\begin{array}{c}\text { Lower } \\
\text { boundary }\end{array}$ & $\begin{array}{c}\text { Upper } \\
\text { boundary }\end{array}$ \\
\hline \multicolumn{4}{c}{ Bourgoyne Jr. and Young Jr., 1974 and 1986 [4, 7] } \\
$\left(\mathrm{RPM}_{\mathrm{sf}}\right)_{N}$ & $100[\mathrm{rpm}]$ & - & - \\
$\mathrm{TVD}_{N}$ & $10,000[\mathrm{ft}]$ & - & - \\
$\mathrm{EPP}_{N}$ & $9.00[\mathrm{ppg}]$ & - & - \\
$\left(\mathrm{WOB}_{\mathrm{sf}} / \mathrm{OD}_{\mathrm{bit}}\right)_{N}$ & $4.00[\mathrm{k}-\mathrm{lbf} / \mathrm{in}]$ & - & - \\
$\left(F_{j}\right)_{N}$ & $1,000[\mathrm{lbf}]$ & - & - \\
$a_{1}$ & - & 0.5 & 1.9 \\
$a_{2}$ & - & 0.000001 & 0.0005 \\
$a_{3}$ & - & 0.000001 & 0.0009 \\
$a_{4}$ & - & 0.000001 & 0.0001 \\
$a_{5}$ & - & 0.5 & 2.0 \\
$a_{6}$ & - & 0.4 & 1.0 \\
$a_{7}$ & - & 0.3 & 1.5 \\
$a_{8}$ & - & 0.3 & 0.6 \\
$R$-squared value & - & & N/A \\
\hline
\end{tabular}

\begin{tabular}{|c|c|c|c|}
\hline \multicolumn{4}{|c|}{ Eren, - 2015 [11] } \\
\hline$\left(\mathrm{RPM}_{\mathrm{sf}}\right)_{N}$ & $60[\mathrm{rpm}]$ & - & - \\
\hline $\mathrm{TVD}_{N}$ & $8,000[\mathrm{ft}]$ & - & - \\
\hline $\mathrm{EPP}_{N}$ & $9.00[\mathrm{ppg}]$ & - & - \\
\hline$\left(\mathrm{WOB}_{\mathrm{sf}} / \mathrm{OD}_{\mathrm{bit}}\right)_{N}$ & $4.00[\mathrm{k}-\mathrm{lbf} / \mathrm{in}]$ & - & - \\
\hline$\left(F_{j}\right)_{N}$ & $1,000[\mathrm{lbf}]$ & - & - \\
\hline$a_{1}$ & & 1.0005588 & 3.29142857 \\
\hline$a_{2}$ & & 0.000191 & 0.004791 \\
\hline$a_{3}$ & & 0.00035 & 0.658851 \\
\hline$a_{4}$ & & 0.000057 & 0.000347 \\
\hline$a_{5}$ & & 0.102882 & 0.852857 \\
\hline$a_{6}$ & & 0.48 & 1.684292 \\
\hline$a_{7}$ & & 0.284286 & 2.587306 \\
\hline$a_{8}$ & & -0.63243 & 1.080511 \\
\hline$R$-squared value & & 0.379 & 0.5395 \\
\hline \multicolumn{4}{|c|}{ Irwan et al., - 2012 [12] } \\
\hline$\left(\mathrm{RPM}_{\mathrm{sf}}\right)_{N}$ & $100[\mathrm{rpm}]$ & - & - \\
\hline $\mathrm{TVD}_{N}$ & $10,000[\mathrm{ft}]$ & - & - \\
\hline $\mathrm{EPP}_{N}$ & $9.00[\mathrm{ppg}]$ & - & - \\
\hline$\left(\mathrm{WOB}_{\mathrm{sf}} / \mathrm{OD}_{\mathrm{bit}}\right)_{N}$ & $4.00[\mathrm{k}-\mathrm{lbf} / \mathrm{in}]$ & - & - \\
\hline$\left(F_{j}\right)_{N}$ & $1,000[\mathrm{lbf}]$ & - & - \\
\hline$a_{1}$ & & \multicolumn{2}{|c|}{3.91} \\
\hline$a_{2}$ & & \multicolumn{2}{|c|}{0.0000945} \\
\hline$a_{3}$ & & \multicolumn{2}{|c|}{0.0000686} \\
\hline$a_{4}$ & & \multicolumn{2}{|c|}{0.000864} \\
\hline$a_{5}$ & & \multicolumn{2}{|c|}{0.37} \\
\hline$a_{6}$ & & \multicolumn{2}{|c|}{2.23} \\
\hline$a_{7}$ & & \multicolumn{2}{|c|}{0.025} \\
\hline$a_{8}$ & & \multicolumn{2}{|c|}{0.67} \\
\hline$R$-squared value & & \multicolumn{2}{|c|}{ N/A } \\
\hline
\end{tabular}

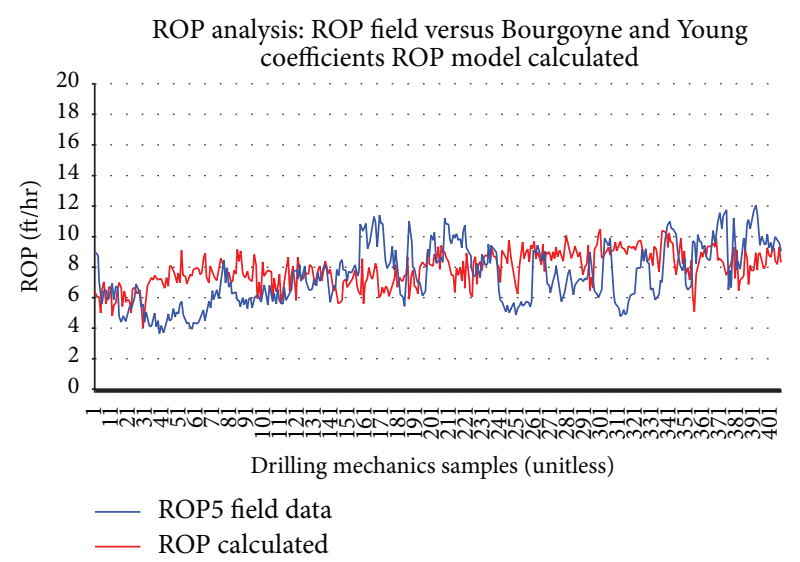

FIGURE 6: Result depth-based ROP graph of the simulation with author-suggested values.

Based on the already obtained results from the first and second simulations, and the results of other authors, a new set of starting coefficients and normalization factors are proposed with the aim of improving fitting the field and the calculated ROP more adequately (Tables 7 and 8).

It can be observed that the relative error value (0.266) and also the graphical response (Figure 6) of the simulation (so the calculated ROP) values are fitting the actual measured field data much more consistently than in case of the first two simulations. These more reliable results are related to the changed coefficient values and normalization factors. Despite the better fitting, there is still room for improvements and validation of the results on more field data.

\section{Summary and Conclusion}

Drilling operations in presalt layers is a challenge for the petroleum industry in many perspectives. One of the most important perspectives from both technical and economic sides is the decreased ROP. Increasing the ROP can be one of the keys to success, so deeper understanding of the ongoing processes, properties, and driving mechanisms of the ROP is crucial. The Bourgoyne and Young ROP model is a viable approach to understand and calculate the abovementioned details, but further considerations, data mining, and recurrent investigation are necessary.

The simulations in this paper show improving results considering presalt drilling data, but more simulations and actual field data are necessary for further development. Alteration of the original model, that is, adding more functions, for example, vibrations, changing range of coefficients range, and normalization factors, can also be a way for further improvements as it is stated in the publication. It is important to highlight that the BYM was not specifically developed for PDC but roller-cutter-bit type; it has adequately responded and showed reliable simulation results. Nevertheless, further adjustment of the model could lead to better match of simulation and real life results.

It was conclusive that relative error enabled the evaluation of the simulation and real life data more adequately than what 
TABLE 7: Current authors' proposed values, 2015.

\begin{tabular}{lccc}
\hline Parameter & $\begin{array}{c}\text { Normalization } \\
\text { factor }\end{array}$ & $\begin{array}{c}\text { Lower } \\
\text { boundary }\end{array}$ & $\begin{array}{c}\text { Upper } \\
\text { boundary }\end{array}$ \\
\hline$\left(\mathrm{RPM}_{\mathrm{sf}}\right)_{N}$ & $60[\mathrm{rpm}]$ & - & - \\
$\mathrm{TVD}_{N}$ & $11,200[\mathrm{ft}]$ & - & - \\
$\mathrm{EPP}_{N}$ & $9.00[\mathrm{ppg}]$ & - & - \\
$\left(\mathrm{WOB}_{\mathrm{sf}} / \mathrm{OD}_{\text {bit }}\right)_{N}$ & $4.00[\mathrm{k}-\mathrm{lbf} / \mathrm{in}]$ & - & - \\
$\left(F_{\mathrm{j}}\right)_{N}$ & $1,000[\mathrm{lbf}]$ & - & - \\
$a_{1}$ & - & 0.5 & 3.91 \\
$a_{2}$ & - & 0.000001 & 0.004791 \\
$a_{3}$ & - & 0.000001 & 0.658851 \\
$a_{4}$ & - & 0.000001 & 0.000864 \\
$a_{5}$ & - & 0.102882 & 2.0 \\
$a_{6}$ & - & 0.4 & 2.23 \\
$a_{7}$ & - & 0.025 & 2.587306 \\
$a_{8}$ & - & 0.3 & 1.080511 \\
\hline
\end{tabular}

TABLE 8: Results of the simulation with author proposal aiming to minimize the relative error.

\begin{tabular}{lccc}
\hline & $\begin{array}{c}\text { Lower } \\
\text { boundary } \\
\text { [unitless] }\end{array}$ & $\begin{array}{c}\text { Upper } \\
\text { boundary } \\
\text { [unitless] }\end{array}$ & $\begin{array}{c}\text { Calculated } \\
\text { Coefficients } \\
\text { [unitless] }\end{array}$ \\
\hline$a_{1}$ & 0.5 & 3.91 & 0.849165 \\
$a_{2}$ & 0.000001 & 0.004791 & 0.000001 \\
$a_{3}$ & 0.000001 & 0.658851 & 0.000001 \\
$a_{4}$ & 0.000001 & 0.000864 & 0.000001 \\
$a_{5}$ & 0.102882 & 2.0 & 0.102882 \\
$a_{6}$ & 0.4 & 2.23 & 0.400000 \\
$a_{7}$ & 0.025 & 2.587306 & 0.025000 \\
$a_{8}$ & 0.3 & 1.080511 & 1.080511 \\
Relative error & & 0.2661461 & \\
\hline
\end{tabular}

$R$-squared allowed. Moreover, by applying a wider range of applicable drillability coefficients and normalization factors, the relative error showed improvements from $46 \%$ down to $27 \%$, a gain of about $20 \%$.

\section{Nomenclature}

TVD: True vertical depth [feet]

$\mathrm{TVD}_{N}$ : True vertical depth normalization value [feet]

EPP: Actual equivalent pore pressure gradient [pounds/gallon]

$\mathrm{EPP}_{N}$ : Actual equivalent pore pressure normalization value [pounds/gallon]

ECD: Actual equivalent circulating density [pounds/gallon]

$\mathrm{WOB}_{\mathrm{sf}}$ : Surface measured weight on bit [kilopounds]

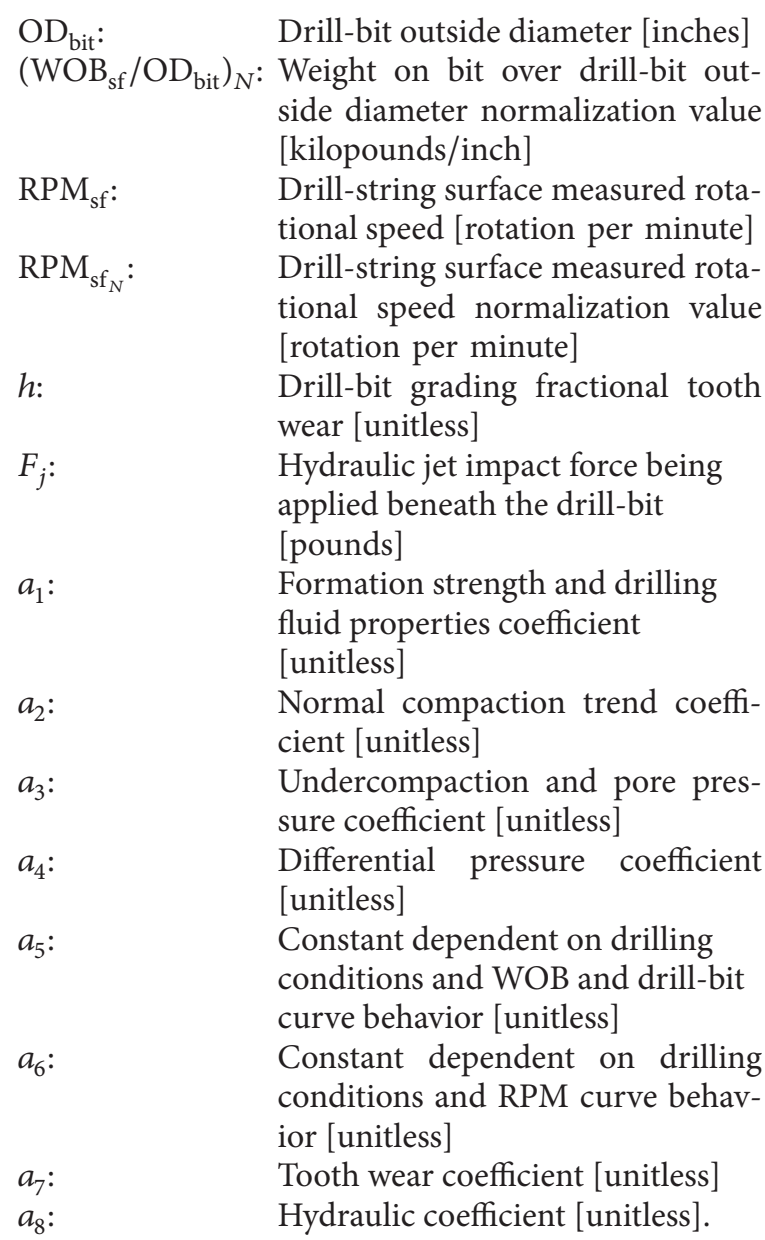

\section{Conflict of Interests}

The authors declare that there is no conflict of interests regarding the publication of this paper.

\section{Acknowledgments}

The authors would like to disclose gratitude to the Chair of Drilling and Completion Engineering from the Montanuniversität Leoben, Austria, to the Coordenação de Aperfeiçoamento de Pessoal de Nível Superior (CAPES) and to the Agência Nacional do Petróleo, Gás Natural e Biocombustíveis (ANP) by means of the BEX 0506/15-0 and PRH48ANP/MCTI.

\section{References}

[1] R. A. Cunningham, Laboratory Studies of the Effect of Rotary Speed on Rock-bit Performance and Drilling Cost, American Petroleum Institute, 1960.

[2] W. C. Maurer, "The 'Perfect-cleaning' theory of rotary drilling," Journal of Petroleum Technology, vol. 14, no. 11, 1962.

[3] E. M. Galle and H. B. Woods, Best Constant Weight and Rotary Speed for rotary Rock Bits, American Petroleum Institute, 1964.

[4] A. T. Bourgoyne Jr. and F. S. Young Jr., "A multiple regression approach to optimal drilling and abnormal pressure detection," 
Society of Petroleum Engineers Journal, vol.14, no. 4, pp. 371-384, 1974.

[5] M. G. Bingham, A New Approach to Interpreting Rock Drillability, Petroleum Publishing Company, 1965.

[6] T. M. Warren, "Drilling model for soft-formation bits," Journal of Petroleum Technology, vol. 33, no. 6, 1981.

[7] A. T. Bourgoyne Jr., Applied Drilling Engineering Handbook, vol. 2, Society of Petroleum Engineers (SPE), Richardson, Tex, USA, 1986.

[8] M. Carminatti, B. Wolff, and L. Gamboa, "New exploratory frontiers in Brazil," in Proceedings of the 19th World Petroleum Congress (WPC '08), WPC-19-2802, Madrid, Spain, June-July 2008.

[9] M. R. Mello, A. A. Bender, N. C. A. Filho, and E. De Mio, "Giant sub-salt hydrocarbon province of the greater campos Basin, Brazil," in Proceedings of the Offshore Technology Conference OTC Brasil, Rio de Janeiro, Brazil, October 2011.

[10] P. R. Johann, A. F. Martini, A. Maul, and J. P. P. Nunes, "Reservoir geophysics in Brazilian pre-salt oilfields," in Proceedings of the Offshore Technology Conference (OTC '12), OTC-23681-MS, Houston, Tex, USA, April 2012.

[11] T. Eren, Real-time-optimization of drilling parameters during drilling operations [Ph.D. thesis], Middle East Technical University, 2015.

[12] S. Irwan, "Optimization of weight on bit during drilling operation based on rate of penetration model," Journal Universitas Pasir Pengaraian, vol. 4, no. 1, 2012.

[13] F. E. Dupriest and W. L. Koederitz, "Maximizing drill rates with real-time surveillance of mechanical specific energy," in Proceedings of the SPE/IADC Drilling Conference, Society of Petroleum Engineers, Amsterdam, The Netherlands, February 2005.

[14] I. Waisberg, "Brazil's Pre-Salt Layer," University of Stanford, 2015, http://large.stanford.edu/courses/2011/ph240/waisberg1/.

[15] T. David and A. Knascimento, Pre-salt occurrences close to the shores of South America and Africa, 2015, http://www.2blstconsulting.com/wp-content/uploads/2012/10/Petrobras_Pre-salt_ Santos-basin_Campos-Basin_Esperito-Santo-Basin_Map.jpg.

[16] J. R. Eckel, "Microbit studies of the effect of fluid properties and hydraulics on drilling rate," Journal of Petroleum Technology, vol. 19, no. 4, pp. 541-546, 1967.

[17] R. H. McLean, “Crossflow and impact under jet bits," Journal of Petroleum Technology, vol. 16, no. 11, 1964.

[18] T. M. Warren and W. J. Winters, "The effect of nozzle diameter on jet impact for a tricone bit," Society of Petroleum Engineers Journal, vol. 24, no. 1, pp. 9-18, 1984. 


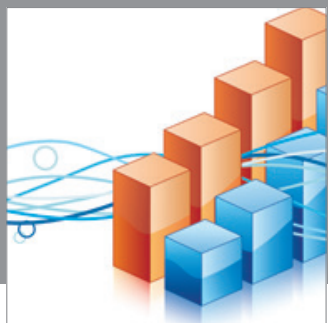

Advances in

Operations Research

mansans

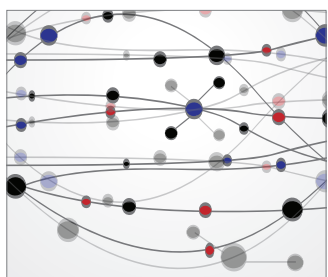

The Scientific World Journal
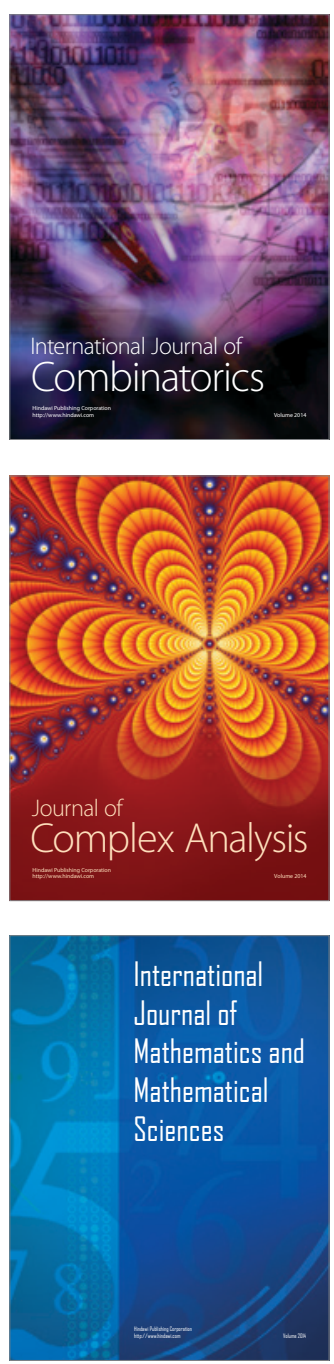
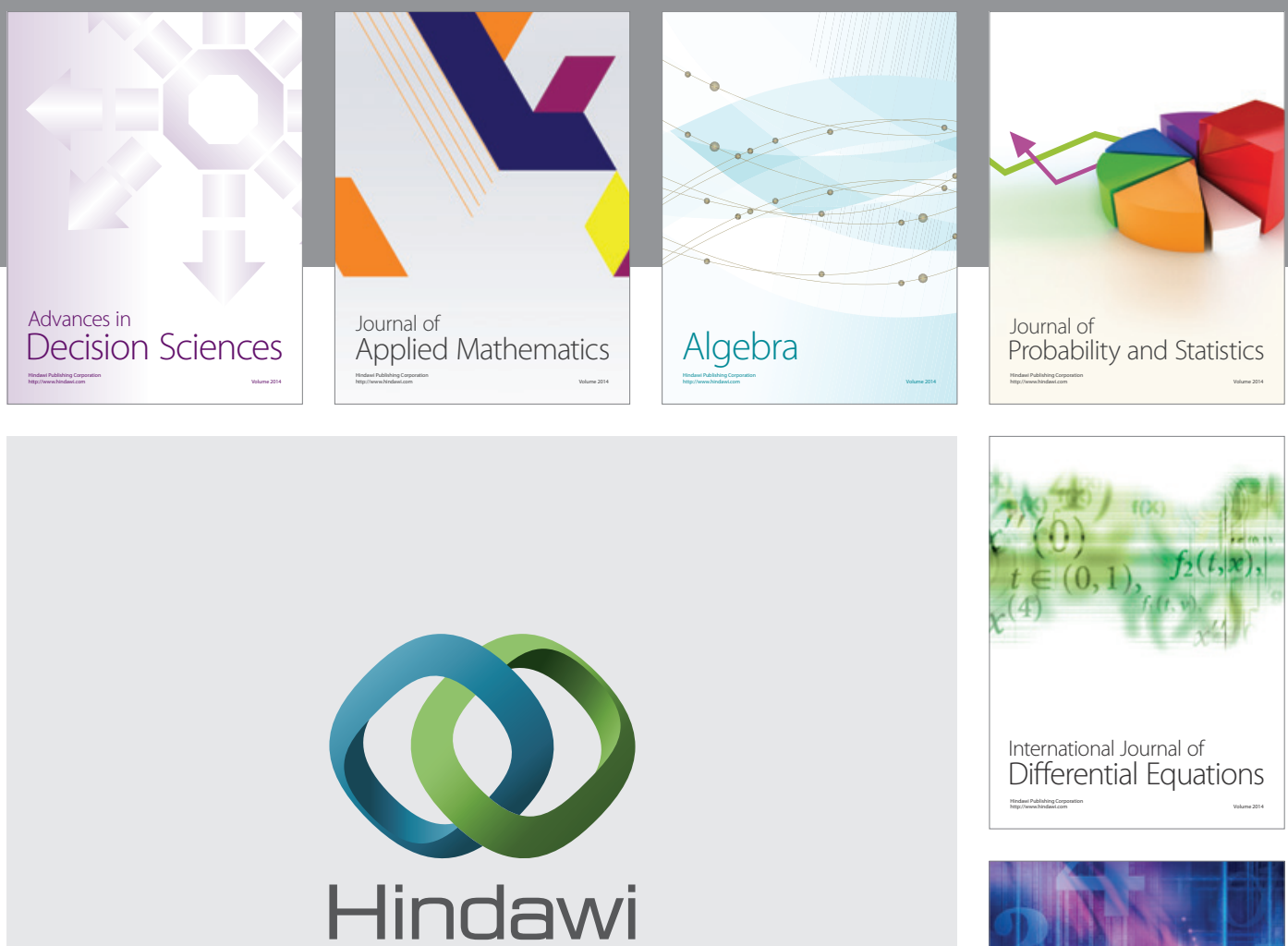

Submit your manuscripts at http://www.hindawi.com
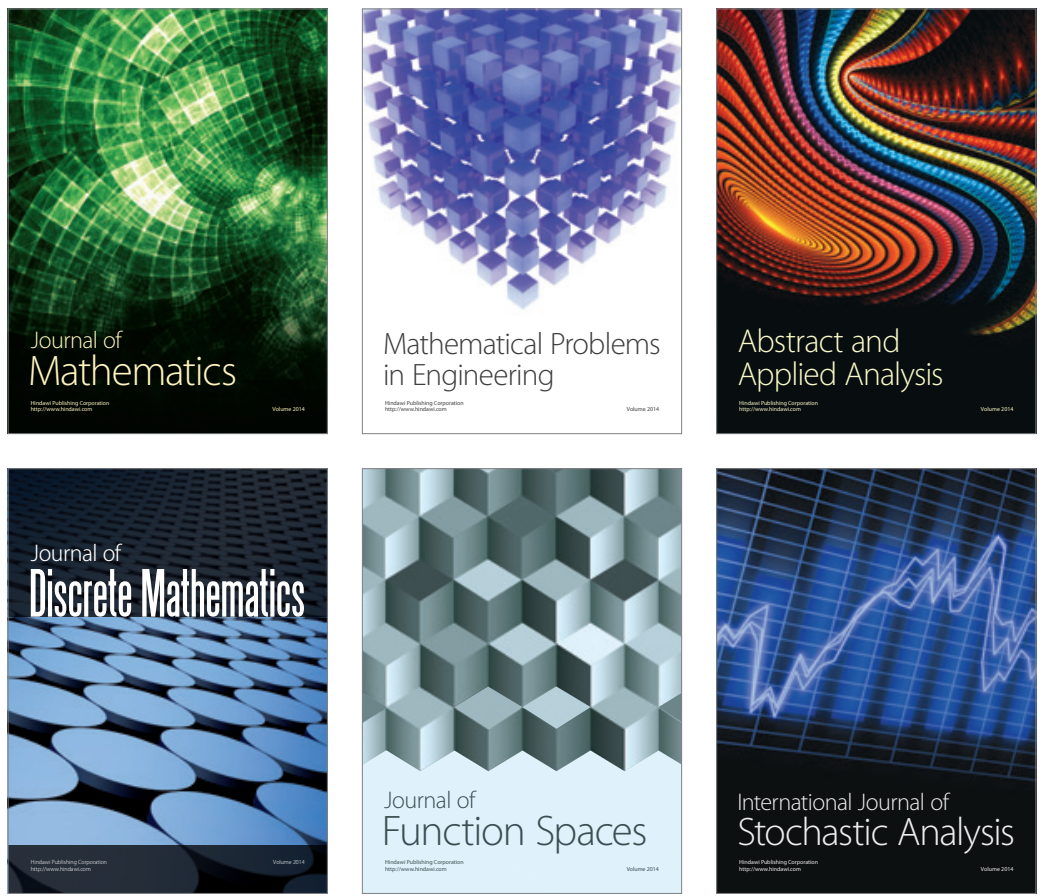

Journal of

Function Spaces

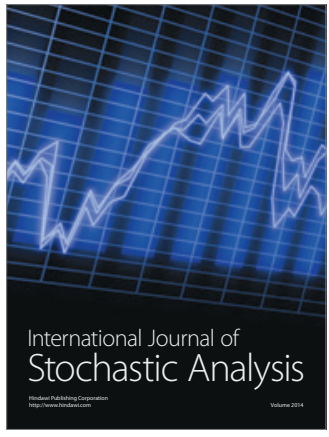

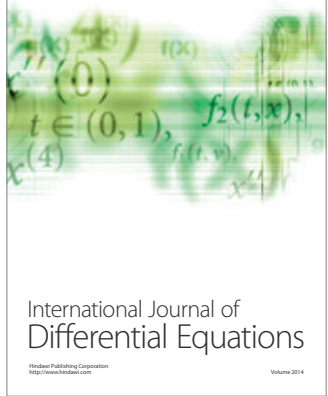
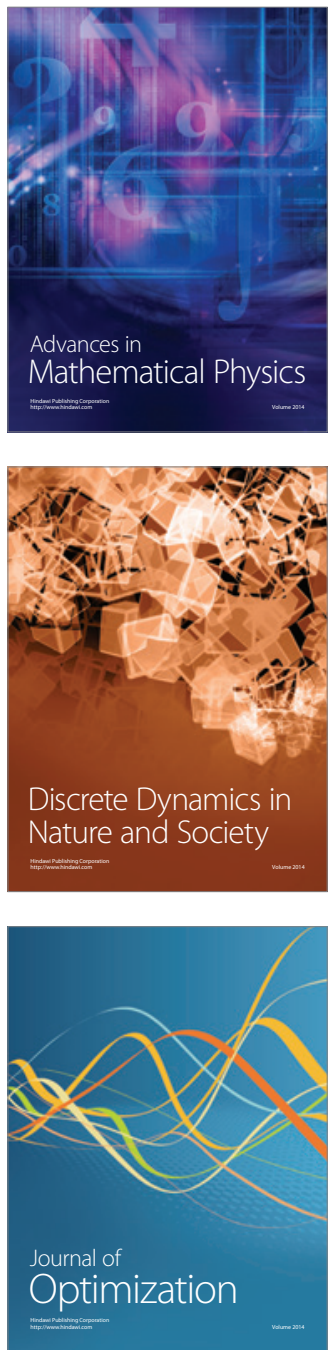